\title{
De artesãos a artistas: um estudo com ceramistas de Tonalá, México.
}

\author{
VANESSA FREITAG \\ Doctora en Ciencias Sociales - Antropología Social (CIESAS-Occidente) \\ Profesora investigadora de la Universidad de Guanajuato \\ freitag.vane@gmail.com
}

\begin{abstract}
Resumo
Pensar o trabalho artesanal de artesãos mexicanos que se inserem no circuito da arte (através de exposições artísticas e participação em concursos de artesanato) é a intenção deste artigo. Ao mesmo tempo, pretende repensar sobre como os conceitos de arte e artesanato foram sendo construidos ideologicamente ao longo do tempo. Neste sentido, embora artesãos se destaquem por apresentar trabalhos com riqueza estética e conceitual, suas obras continuam sendo vistas e valorizadas socialmente como artesanato. Faz-se necessário criar um espaço para questionar os modos de ver o artesanato atualmente, levando em consideração as diferentes tipologias que caracterizam o oficio.
\end{abstract}

Palavras-chave: arte; artesanato; estética artesanal; processo criativo; artesãos mexicanos.

\section{Introdução}

$\mathrm{O}$

PRESENTE TEXTO objetiva pensar o trabalho artesanal como uma prática criativa cujas mãos e mentes não estão dissociadas como se costuma concebê-lo, num primeiro momento. Em tempos nos quais as discussões sobre o visual e as visualidades são temas recorrentes (e urgentes), discursar sobre as práticas artesanais parece meio "fora do eixo" de interesse dos estudos sobre cultura e arte. Neste sentido, pretendo reiterar sobre a necessidade de pensar o trabalho artesanal além de meras atividades motoras e sem propósito transcendental que o de decorar ambientes inóspitos ou comerciais.

A base empírica deste artigo está fundamentada nas experiências tidas pesquisando o contexto artesanal de três famílias de artesãos mexicanos entre 2009 e 2010 respectivamente. No plano teórico, se revisitará textos como os de Richard Sennett (2009), Roger Bastide (2006), Howard Becker (1982), Victoria Novelo (1997), Adolfo Colombres (2014) entre outros, na tentativa de construir um argumento que reconheça o trabalho de alguns artesãos e artesãs como artístico, ou seja, como arte.

Sabemos que esta afirmação dá margem para um debate profícuo e necessário e possivelmente, não se chegará a uma conclusão unívoca a respeito. No entanto, quando se pensa em artesãos, artesanato e arte popular, tem-se em mente uma definição muito específica, ou seja, de que se trata de um trabalho manual e repetitivo, exclusivamente. No entanto, os e as artesãs que bordam, que criam um objeto cerâmico, que entalham a madeira, por citar alguns exemplos, possuem uma percepção visual dos materiais que manipulam, buscam harmonizar as cores e formas, têm sensibilidade para organizar os materiais que são próprios do trabalho que realizam. Em outras palavras, possuem um amplo sentido estético 
(GOMES LIMA em KELLER, 2011). Então, o artesanato é definido pelo trabalho que se realiza com as mãos, ou seja, "originalmente, a palavra artesanato significa um fazer ou o resultado desse fazer que tem por característica o fato de que todo o processo de produção é manual' (GOMES LIMA, 2009, p.96). Mas este fazer manual não está dissociado dos universos de significados, símbolos e sentidos que o artesão imprime no seu trabalho, pelo contrário, geralmente é motivado por estes.

Portanto, penso que o artesanato é uma arte: no sentido tradicional do termo, é a habilidade de criar coisas bem feitas e de saber executá-las com as mãos; mas também, se trata de um objeto artístico imbuído de significados (tanto para o artesão que o cria quanto para o seu respectivo consumidor), porque nos remete à identidade cultural de um povo, de uma comunidade ou de um artesão em particular. Penso que também pode-nos conectar com nossas lembranças, evocar um tempo e um espaço determinado, ser um dispositivo de afetos. Quando vejo um artesanato, me sinto imediatamente interessada por suas formas, cores, materiais, significados e algumas vezes, pelo uso que posso dar-lhe. Por isso, considero que se trata de um objeto que nos provoca empatia quase imediata: "o artesanato não nos conquista únicamente por causa de sua utilidade. Vive em cumplicidade com os nossos sentidos e talvez por isso, seja tão dificil desapegarmos dele." (Paz, 1988, p.16, tradução livre da autora).

Dito isto, a fim de expor a compreensão sobre o tema, busco contextualizar e discutir algumas das contribuições encontradas durante a pesquisa realizada com artesãos em solo mexicano.

\section{Sobre como ressignificar 0 artesanato e o trabalho do artesão: uma experiência em Tonalá, México}

No México, o artesanato forma parte da vida cotidiana da maioria das pessoas. Tanto é que cada estado possui um tipo de artesanato em particular, e consequentemente, artesãos e artesãs com um refinado sentido estético.Tais objetos evidenciam a expressão material da confluência das culturas indígenas com a espanhola, da rural com a urbana, da tradição com a modernidade. Neste ponto, tem um parecido com a história do artesanato brasileiro posto que este também é fruto da relação interétnica, mas no nosso caso, do intercambio que houve entre índios, brancos e negros (Frota, 1976).

Esta pesquisa nasce do interesse em estudar a artesãos mexicanos que viviam e trabalhavam como tal no contexto urbano. Portanto, considerei conveniente realizar um estudo de corte etnográfico numa localidade que integra a zona metropolitana da cidade de Guadalajara, estado de Jalisco. Tal é o caso da cidade de Tonalá, cuja primeira visita, impactou-me positivamente. Guardo na memória esta experiência de ver uma amplia variedade de artesanatos de todo tipo, cores, tamanhos e finalidades, expostos nas calçadas das principais ruas da cidade.Vinda de um contexto totalmente diferente, o que via era algo novo, sedutor e inquietante.

Tonalá é um município com quase 500 mil habitantes distribuídos em mais de 20 pequenos bairros (que mais parecem pequenas cidades dentro da cidade). O centro é tipicamente mexicano: uma pracinha perto da igreja, um mercado público, muitas lojinhas e comércios de pequeno porte. Os moradores ainda mantêm o costume de fazer a feira - "el mandado"- no mercado da praça ou nas "tiendas de abarrotes", que é uma loja minúscula e abarrotada de produtos básicos, muito prático para as necessidades da vida cotidiana. Outra particularidade de Tonalá é a principal fonte de renda da grande maioria de seus habitantes: o artesanato, especialmente, a cerâmica.

\section{0 artesanato tonalteca}

Tonalá é nacionalmente conhecida como o berço do artesanato em Jalisco e se destaca pela elaboração de técnicas artesanais de origem pré-hispânica (como o barro bruñido) e outras especialidades próprias da localidade. Durante minha estada nesse povoado, aprendi a reconhecer os diferentes tipos de artesanato e de artesãos existentes, a destacar: a. artesãos tradicionais, cujos processos artesanais foram herdados de geração em geração; b. artesãos que "maquilan", ou seja, compram peças previamente produzidas por outros artesãos e se dedicam a decorá-las e vendê-las; c. artesãos que produzem objetos utilitários e comerciais; d.artesãos considerados artistas (ou artistas populares), que elaboram peças exclusivas, participam de concursos e inovam constantemente. Sobre este último, pretendo aprofundar um pouco mais ao longo do texto.

Como já foi dito, o artesanato que se produz em Tonalá não é um caso isolado quando se pensa em México: de norte a sul do país podemos encontrar artesãos genuínos, verdadeiros "representantes" da cultura nacional, provindos tanto de contextos urbanos como de comunidades indígenas. $\mathrm{O}$ artesanato fomenta o turismo e a vinda de estrangeiros de todas as partes do mundo, mas especialmente, dos Estados Unidos e da Europa. Atualmente, este setor se enfrenta com o competitivo mercado de artesanato de procedência asiática (chinês). Tal mercado representa um importante concorrente dado que alimenta a comercialização de artesanato que é a cópia das peças originalmente criadas pelos artesãos tonaltecas. Se trata de um problema que se agrava com o passar dos anos e os artesãos não têm orientação especializada sobre como proteger seu trabalho da pirataria asiática. 
No entanto, uma alternativa que encontram para se defender dessa desleal competição é a invenção de novas linhas artesanais, imprimindo identidade e estilo próprio em cada peça criada. Se tem algo que o mercado asiático não pode imitar é o conhecimento técnico e o refinado sentido estético desses criadores, ou nas palavras de Sennett (2013, p.13 tradução livre da autora): "toda atividade artesã se fundamenta em alguma destreza técnica desenvolvida em alto grau".

Novelo (1997) define o artesanato mexicano como obras plásticas, produtos de um processo de trabalho particular onde o produtor combina seus conhecimentos das matérias-primas com o design, cujas habilidades e destrezas, criarão objetos manuais providos de elementos estéticos e conceituais.

Através do trabalho artesanal, os artesãos elaboram objetos tanto de caráter decorativo, utilitário e também artístico, condensando aspectos econômicos, sociais e culturais que expressam a visão de mundo de povos indígenas e mestiços. Por isso, Martínez-Peñaloza (1981) vê o artesanato como uma possibilidade para conservar e transmitir conhecimentos próprios de um povo, dado que constitui um aspecto importante na elaboração da indumentária, na produção de utensílios domésticos, na simbologia cerimonial e nas festividades de uma determinada sociedade. Além disso, representa o universo de formas, cores, texturas e materiais que se imprimem na vida individual e coletiva de quem os realiza.

Mas é importante mencionar que os artesãos não fazem artesanato somente por obra da "inspiração": são processos de trabalho que estão profundamente arraigados ao contexto de sua realidade e respondem à necessidades religiosas ou culturais da comunidade nas quais estão inseridos, por isso mesmo, muitos desses artesãos são reconhecidos como tradicionais (Zapata y Suárez, 2007).

Durante o trabalho de campo realizado em Tonalá/Jalisco, primeiramente se fez uma visita informal a mais de 30 "talleres" de artesãos, onde encontrei pelo menos cinco tipos de cerâmica predominantes nesta localidade: barro bruñido, barro bandera, barro petatillo, barro betus e barro canelo, realizadas com propósitos diversos: comerciais, utilitários, decorativos e/ou artísticos.

A modo de aclaração, reitero que existem diferentes tipos e usos de artesanato neste país. Se tomamos como ponto de partida seu propósito comercial, poderíamos mencionar algumas tipologias de artesanato consideradas por Davy (2011): objeto artesanal doméstico (de uso exclusivamente cotidiano, tais como, vestuário e utensílios domésticos); objeto artesanal comercial (miniaturas e souvenirs confeccionados em grandes quantidades, dirigidos ao turismo); objetos de criação artesanal (de qualidade variável, função meramente decorativa) e objetos artesanais que apresentam uma "meta estética", ou seja, quando as fronteiras entre arte e artesanato se tornam "movediças" (Goldstein, 2014), dado que são objetos únicos e exclusivos.

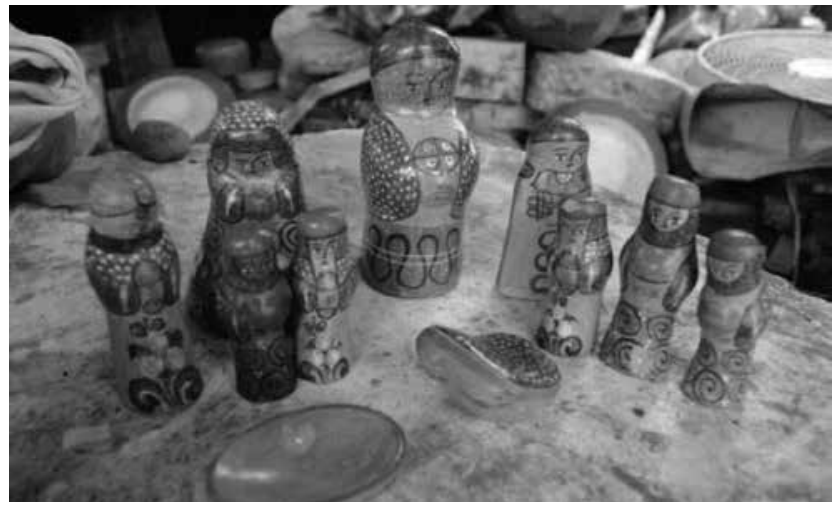

Figura 1 - Peças em barro bruñido comercial.

Fotografia: Vanessa Freitag, Tonalá, 2010.

No entanto, para fins deste artigo, considerei interessante discutir o caso de artesãos que possuem diferentes tipos ou linhas artesanais e especialmente, que criam objetos para concursos a fim de ser expostos em galerias e museus. Me refiro a um tipo de artesanato e de artesão que se encontra entre as tênues fronteiras que separam a arte erudita da popular (Frota, 1976). Portanto, selecionei três famílias para poder realizar o estudo, tomando como critério o caráter tradicional e artístico das peças criadas por elas. Essas famílias produziam artesanato nos seguintes tipos de cerâmica:

\section{a) Barro Bruñido:}

Bruñir significa polir. As peças criadas em barro bruñido são assim caracterizadas pelo processo de decoração das mesmas. Antes de irem ao forno, são pintadas com óxidos e depois de secas, são polidas com uma pequena pedrinha que produz um intenso brilho natural a partir da frotação da mesma sobre a superficie dos objetos. Só depois desse processo é que as peças vão ao forno e se transformam em barro bruñido ou cerâmica polida, como podemos ver na imagem a seguir.

\section{b) Barro Bandera:}

Cerâmica cujo decorado levam as cores da bandeira mexicana: verde, branco e vermelho. Todas as peças têm uma base vermelha e posteriormente, são decoradas com arabescos e figuras oriundas do imaginário coletivo e popular dos artesãos. Para desenhar essas imagens, usam óxidos nas cores branco e verde, como podemos observar na imagem abaixo:

\section{c) Barro Betus:}

A terceira forma de decorar as peças artesanais tonaltecas é através do barro betus. Levam este nome pelo modo como os artesãos produzem o brilho da superficie 


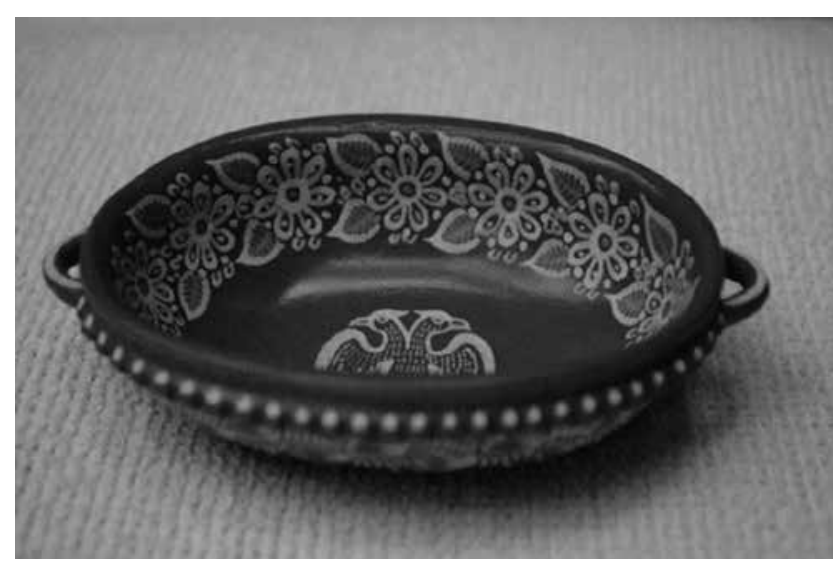

Figura 2 - Peça artística em barro bandera.

Fotografía: Vanessa Freitag, Tonalá, 2010.

cerâmica. Betus provêm de uma árvore conhecida com o mesmo nome, cujo caule produz uma resina natural e transparente que é recolhida pelo artesão e derretida no fogo. Depois de queimada, a cerâmica é decorada com pigmentos naturais a base de água e finalmente, se passa a resina como forma de proteger a cor e conferir brilho à peça. Reconhece-se que um artesanato está decorado em barro betus pela sua textura e pelo cheiro forte que a mesma exala (mas com o tempo, esse odor se suaviza). A produção em cerâmica betus se reduziu drasticamente nas últimas décadas e isto se deve a alguns fatores: o primeiro, tem a ver com o crescimento acelerado da vila e que deu lugar à urbanização. Isto gerou um importante problema para os artesãos dado a dificuldade de abastecimento de matérias primas, começando pelo barro e culminando na deflorestação de muitas áreas verdes. Como consequência, os jovens artesãos que desejam trabalhar a técnica antiga do barro betus se encontram em dificuldades para localizar as árvores de tipo "betus". Atualmente a maioria dos artesãos que trabalha esse tipo de cerâmica já usa tintas comerciais que dispensam a aplicação da resina natural. Por isso mesmo, o barro betus passou a ser considerado o estilo de cerâmica criada, cujas figuras são identificadas como surrealistas e já não tanto pela resina que adorna e protege as peças.

Exposto e identificado alguns dos tipos de cerâmicas produzidas pelos tonaltecas, gostaria de discutir o conceito de artesão-artista no caso mexicano utilizando alguns teóricos do campo da antropologia e da sociologia da arte.

\section{De artesão a artista: revisitando a problemática dos conceitos.}

El artesano representa la condición específicamente humana del compromiso (Sennett, 2009).

El arte no pudo nacer sin la colaboración de los individuos (Roger Bastide, 2006).

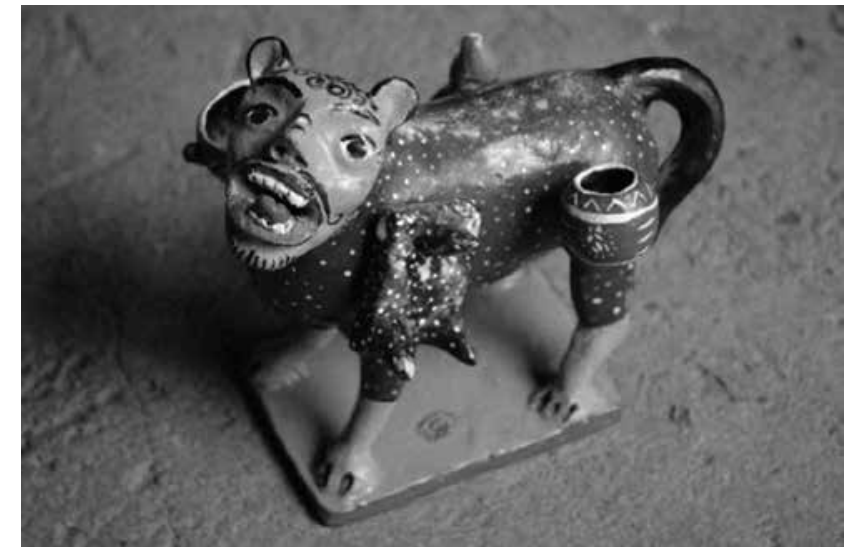

Figura 3 - Peça comercial em barro betus.

Fotografia: Vanessa Freitag, Tonalá, 2010

Neste trabalho, parto da ideia de que artesãos e artistas compartem duas esferas importantes no seu processo criativo: a primeira, tem a ver com o aprendizado manual, ou seja, com o domínio e aperfeiçoamento de uma técnica e linguagem particular, seja ela qual for: cerâmica, trançagem, pintura, escultura, entre outras. E a segunda, estreitamente relacionada com a primeira, tem a ver com a intenção, o sentido e o significado daquilo que produzem. Portanto, penso que tanto artistas como artesãos realizam uma atividade de cunho estético e criativo. Sobre este tema, coincido com Gomes Lima (2009) quando nos traz uma interessante contribuição ao resolver, pelo menos conceitualmente, a possível dicotomia entre arte e artesanato, entre artesão e artista. $\mathrm{O}$ autor afirma que se faz necessário reservar o termo artesanato para:

referir-se ao processo de produção do objeto, à tecnologia que, predominantemente executada com as mãos, dá forma ao objeto, independente do fato de serem mãos eruditas ou populares. (...) Em um outro plano, pode-se discursar sobre esse mesmo objeto com a preocupação de desvelar questões de estética - de equilíbrio de massas, de proporções (ou de desproporções), de contrastes entre forma e fundo, entre claro e escuro, de ritmo, de cores - , de conteúdos simbólicos - de campos de significados, expressos ou latentes - e de representações. Aí, trata-se de arte. (Gomes Lima, 2009, p.101).

Poderíamos ver o artesanato como uma arte que têm critérios próprios que fundamentam e legitimam seu valor como tal? Ou estaríamos forçando a vê-lo com os mesmos critérios e normas que legitimam a arte considerada acadêmica ou erudita? Este é um problema que continua sem se resolver. No entanto, penso que a definição de Gomes Lima é apropriada para o caso do artesanato, dado que este pode ser pensado a partir das características particulares de sua criação (entre elas, a feitura manual), como também, superar os propósitos de objeto utilitário e decorativo, e se inclinar a ser um objeto artístico (Becker, 1982). Sem que para 
isso, o artesão deixe de identificar-se como tal. Me parece que as habilidades e campos nos quais se inserem o objeto artesanal, se tornam cada vez mais complexos. Os artesãos conseguem se adaptar a diferentes âmbitos de circulação de seus objetos. No mercado artesanal, penso que há espaço para todo o tipo de artesão, muito embora, os mesmos estejam regrados por normas que limitam e condicionam o trabalho de uns em detrimento de outros. Por exemplo, ao ampliar os espaços de visibilidade de uma peça artesanal, como seria sua apresentação em um museu ou galeria, implica para o artesão a conquista de um tipo de reconhecimento e diferenciação se comparado com o trabalho daqueles que não expõem nestes contextos.

De um modo geral, podemos dizer que a discussão sobre os conceitos de arte, artesanato ou de cultura popular são cada vez mais abundantes e problematizados desde diferentes disciplinas teóricas como a história e crítica de arte, a filosofia, os estudos culturais, a sociologia, a antropologia. Como tal, as posturas de Sennett (2009 y 2013), Good (2010), Bourdieu (2010), Belting (2007), Bastide (2006), Gell (1998), Becker (1982) nos ajudam a entender o papel social da arte, do artista, do artesão e do artesanato na sociedade ocidental.

De acordo com esses teóricos, tanto o conceito de arte como o de artista são construídos desde a perspectiva ocidentalizada da cultura, e com ele surge a concepção de "genialidade" e "individualismo" para conceber a criação de uma obra de arte. Como parte desta ideia ocidentalizada da arte, Good (2010) faz uma importante análise:

(...) existe uma imagem do artista que, desde a época do romantismo, se desdobra como um indivíduo especialmente imaginativo e criativo, dotado de uma visão e um talento fora do comum, que produz obras de modo solitário em momentos de grande inspiração. (...) A autoria individual de obras originais é uma das características nas definições convencionais da arte (Good, 2010, p.47, tradução livre da autora).

Por outro lado, a palavra artesanato vem do latim vulgar artitianus e se refere ao trabalhador que é hábil numa determinada atividade (Pérez Martínez, 2010). Este autor assume o artesanato como um dos mais profundos e eficazes sistemas de comunicação, considerado como mecanismo de transmissão ancestral, de saberes ensinados e aprendidos num contexto familiar. $\mathrm{O}$ artesanato expressa o que compreendemos como cultura e são elementos importantes na constituição da identidade e dos conteúdos da mesma: expressão da espiritualidade, das crenças, dos rituais e dos sistemas simbólicos de uma determinada sociedade.

$\mathrm{Na}$ Grécia antiga, a ideia de arte não estava separada da técnica: "o termo arte, surge do latim ars e contém o sentido originário do grego tekné: arte manual, oficio, habilidade (adquirida através do estudo ou pela prática)"(Tabosa, 2005, p.01). Assim sendo, techné/ars podia ser interpretado como a capacidade ou a destreza humana para elaborar/criar coisas e objetos, como também para executá-los (Shiner, 2010). Esta antiga concepção do artista estava muito mais próxima à nossa atual ideia de "homem de oficios", dado que o artesão/artista grego ou romano "tinha que combinar uma capacidade intelectual para captar princípios com um entendimento prático, com certa destreza e graça"'(Shiner, 2010, p.50). Se retrocedemos no tempo e nos detivermos nas manifestações artísticas pré-históricas, a arte tinha pouca relação com a ideia de beleza, muito menos com a de contemplação estética.

De acordo com Fischer (1983), na sociedade primitiva a arte era um instrumento mágico, uma arma da coletividade humana na luta pela sobrevivência. Portanto, não se tratava de uma produção individual mas coletiva, sendo uma atividade social por excelência. Da mesma forma argumenta o sociólogo da arte Bastide (2006), quando discute a origem social e coletiva da arte definindo-a como uma atividade técnica do homem. Para ambos os autores, a arte estava diretamente relacionada com a prática de rituais (como as pinturas rupestres e as danças), ou para proteger o corpo (como a pintura e o adorno corporal), respondendo assim, a fins utilitários, à satisfação de necessidades coletivas e religiosas. $\mathrm{O}$ conceito de arte tal e como conhecemos atualmente foi uma invenção da modernidade, mais especificamente, a partir do Renascimento.

Para Andrade (1938) é no Renascimento que a beleza se impõe como finalidade nas artes plásticas e se tornou o principal propósito das pesquisas realizadas pelos artistas. Esse fato marca a separação entre o trabalho do artesão e o do artista. Bastide (2006) nos recorda que o artista foi primeiramente, um escravo ou um artesão destituídos de privilégios; não podia pois, melhorar sua condição social além das oferecidas por um abastado mecenas. No Renascimento se forja o conceito de que a elaboração de um trabalho artístico exigia do artista um talento inato ou uma grande habilidade para expressar, através das formas e cores, objetos belos, sem um fim utilitário mais do que o de provocar prazer estético. Pouco a pouco, se cria o mito do artista, ou seja, uma pessoa com um "dom" especial:

(...) o status de qualquer atividade em particular, como uma atividade fundamental que requer dos dotes do artista ou como simples apoio, pode mudar. Como podemos ver, as pinturas que alguma vez foram pensadas como um trabalho especializado, mas não mais que isso, foram definidas como algo especial no Renascimento (Becker, 1982, p.17, tradução livre da autora).

Mas a imagem do artesão/artista como um trabalhador completo, que possui tanto imaginação, inventividade e graça como destreza manual, foi sendo gradualmente modificada. $\mathrm{O}$ artesão passou a ser visto como aquele que se limita às regras e possui habilidades, e as 
noções de talento, dom e beleza foram conceitos adotados para aludir ao trabalho de um artista (Goldstein, 2014).

Tanto é que a habilidade técnica e manual foi revista e algumas vezes, evitada em muitas das produções artísticas desde a arte moderna, especialmente a partir de Duchamp, da arte conceitual e muitas das obras de arte contemporânea (Michaud, 2007). Goldstein (2014, p.03) reitera que a arte moderna foi construída sobre três pilares fundamentais: a obra de arte precisa ser única e original; não pode ter motivações econômicas, utilitárias ou religiosas; a autoria da obra deve ser reconhecida por seus pares, pela crítica e pelas instituições de arte. Estas três ideias-base usadas para identificar e distinguir um objeto como arte ou outra coisa "são contingentes e associados especificamente à produção artística moderna euroamericana" (Goldstein, 2014, p.04) que, ao mesmo tempo, se tornaram universais e normativas.

Mas neste texto, não pretendo reivindicar o artesanal nas obras de arte contemporânea, e sim, entender como e quando surge a dissociação entre manual e mental, belo e utilitário, entre arte e artesanato. No livro de Richard Sennett (2009), o autor buscou explorar o que acontece quando, na prática do trabalho artesanal, se separam a mão da cabeça, a ciência da técnica, a arte do oficio, para num segundo momento, problematizar criticamente a concepção do artesanato como uma prática exclusivamente manual. Para este autor, todo artesanato se fundamenta numa habilidade desenvolvida em alto grau e que o artesão representa o compromisso de fazer bem os objetos que produz. Diz Sennett (2009, p.33) que, ao criar um novo objeto, o artesão sente recompensa emocional; seu trabalho se baseia numa realidade tangível e pode se sentir orgulhoso do que faz.

No entanto, a sociedade conseguiu bloquear essas recompensas no passado e isto permanece atualmente, sobretudo quando a atividade prática e a habilidade técnica passam a ser relegadas e desvalorizadas ao longo do tempo. Isto me parece muito significativo para poder entender o contexto de artesãos-artistas tonaltecas.

\section{0 trabalho criativo do artesão-artista tonalteca.}

O aprendizado artesanal acontece de muitas maneiras: pode-se dar no contexto familiar ou como ajudante de algum artesão experiente; pode ocorrer tomando um curso numa escola especializada ou por conta própria, entre outras situações possíveis. No caso dos artesãos tradicionais mexicanos, os quais foram considerados neste estudo, os primeiros passos do oficio se deram no âmbito familiar. Crianças e jovens aprendizes costumam ser guiados por parentes ou vizinhos; mas eventualmente, essa inserção inicial se dá quando ainda são ajudantes de outros artesãos.

Neste sentido, aprende-se a ser artesão fazendo artesanato e praticando o oficio, pelo menos, é assim como muitos dos tradicionais artífices mexicanos se involucram com o trabalho. Nessas famílias, o artesanato é parte da tradição e da cultura familiar, e é pois, uma herança transmitida de geração em geração. Mas pertencer a uma família de artesãos não significa que não haja espaço para que cada artesão se desenvolva com um trabalho individual.

Portanto, penso que os modos de apreciação do trabalho artístico e artesanal, assim como, dos objetos criados pelos artesãos e artistas são, antes que nada, formas culturais de olhar:"geralmente, a sociedade ocidental denomina os artesãos pela sua maneira de trabalhar, embora entre eles existam verdadeiros artistas criadores que talvez não se ajustem aos cânones da academia, nem nos seus modos de conceber o aprendizado, nem nos seus modelos"(Novelo, 2002, p.171, tradução da autora). Ainda de acordo com esta autora, esse modo de ver o trabalho artesanal como "não artístico" radica das desigualdades geradas pelo baixo reconhecimento social e econômico da atividade artesanal.

O fato é que me tem chamado muito a atenção o caso de alguns artesãos mexicanos que costumam participar em concursos de artesanato, eventos estes, organizados pelas principais instituições públicas de fomento artesanal no México: Fondo Nacional para el Fomento de las Artesanías (Fonart), Casas de Artesanías, Secretarías de Desarrollo y Turismo, por mencionar algumas delas. A fim de apresentar um trabalho "para concurso", o artesão deverá elaborar uma peça com um alto nível técnico e que condense aspectos identitarios da sua cultura origem. Desta forma, há favorecido o aparecimento de linhas artesanais com um forte apego estético e consequentemente, desvinculadas de uma função utilitária, decorativa ou cerimonial. Isto implica investir longas horas de trabalho numa única peça.

Receber um prêmio num concurso gera algumas "recompensas", tais como: ser reconhecido pelo grupo de artesãos como "um dos melhores", ter sua imagem (e do seu trabalho) difundida pelos meios de comunicação de massa, ter a oportunidade de viajar para participar em feiras e exposições artesanais, e por último, a imagem de seus trabalhos é usada pelo governo local para promover o turismo na cidade. No entanto, mesmo com certo prestígio, grande parte desses artesãos ainda vive em condições de pobreza extrema e carência de recursos econômicos, tal como nos comenta Novelo:

(...) a separação que se faz entre os produtores e suas obras no campo da admiração também tem um ingrediente de discriminação cultural no campo da apreciação estética, pois ao mesmo tempo em que se valoriza uma das expressões culturais de uma sociedade, não se permite o acesso a uma melhor qualidade de vida (Novelo, 2002, p.173, tradução da autora). 
Mas mesmo assim, o trabalho artesanal se caracteriza por uma condição paradoxal: por um lado, simboliza parte das tradições e saberes ancestrais de determinados povos e culturas; por outro, é sinônimo de antigo, precário ou retrógrado mesmo quando se tratem de obras artesanais com um estimado valor estético e conceitual. Neste panorama, surge a figura do artesão-artista.

O termo é abordado pelo sociólogo da arte Howard Becker (1982:316-317) ao considerar a arte e o artesanato um trabalho como qualquer outro. Com isso, contradiz a tradição dominante que considera as obras de arte como produto da inspiração de indivíduos especiais. Diz o autor que são mecanismos especiais que selecionam artistas de não artistas: “(...) os artistas populares se parecem aos artistas canônicos do mundo da arte: eles produzem seus trabalhos e são parte de uma comunidade muito bem organizada"(Becker, 1982: 226, tradução livre da autora).

$\mathrm{Na}$ opinião deste autor, o artesão-artista elabora objetos exclusivos e únicos, com virtuosismo e sentido estético; na maioria das vezes, considera o que faz como arte, e com relativa frequência participa de exposições, produz e comercializa seus objetos para colecionadores de arte. Mas nem sempre se considera a si mesmo como artista dado que a identidade como artesão está fortemente arraigada na imagem que possui de si e do que faz. E quando se considera artista, se refere geralmente ao sentido de "saber fazer" um trabalho bem feito, de conhecer e dominar sua especialidade artesanal:

\section{V.: O senhor se considera um artista?}

J.: Não. Eu acho que não porque, olha, o que eu posso dizer é que nos falta muito para ser um bom artesão. Teríamos que saber de tudo, não somente esta rama do artesanato, né? No nosso ramo sim, podemos dizer que o dominamos, mas não podemos nos considerarmos "mestre". Ou seja, digo isto porque são as pessoas que nos julgam. Tu podes ter uma opinião sobre meu trabalho e outras pessoas podem ter outras. Às vezes te elogiam, às vezes te criticam muito. Nós não somos artistas, somos artesãos que vivemos da arte. Por exemplo, cada artesanato têm suas particularidades, e eu penso que isto não é muito, não é qualquer pessoa que sabe fazer, não é qualquer pessoa que tem a imaginação para fazer isto, não é qualquer um que faz as coisas à pulso, necessitaria adquirir a prática, que levaría tempo, eu penso que levaría bastante tempo para aprendê-la" (Juan José Ramos Medrano, artesão de Santa Cruz de las Huertas, Tonalá, 2010 tradução livre da autora).
A resposta deste artesão é bastante complexa. Primeiramente, ele não se vê como artista, muito embora, considere seu trabalho como arte. Neste caso, descreve seu oficio pela sua capacidade inventiva (ou "ter imaginação"), um componente tão importante quanto a habilidade manual (o "fazer a pulso"). São pois, âmbitos inseparáveis. Logo, atribui ao consumidor de seu trabalho a tarefa de julgar o que faz como arte ou artesanato. Para Bourdieu (1979), um objeto se torna artístico quando é percebido de acordo com uma intenção estética, quer dizer, é apreciado mais pela forma que por sua função.

As autoridades tonaltecas também contribuem para reforçar a identidade artesanal da localidade. No entanto, nos últimos cinco anos, tenho observado o uso de certos termos que reconhecem e identificam o viés artístico do trabalho artesanal. Então, começam a despontar palavras como: "artistas populares", "artistas", e "criadores ou criadores populares" para identificar a este setor ${ }^{1}$. Mesmo assim, todos os artesãos e artesãs entrevistados neste estudo se reconheciam, primeiramente, como artífices muito embora concebessem seu trabalho como uma obra de arte.

Tal é o caso da família Jimón, cuja produção artesanal era muito diversificada. Com relativa frequência, seus integrantes participavam de mostras artesanais e constantemente, criavam diferentes tipos de artesanato. Além disso, se destacavam pela forte participação em concursos e colecionavam premiações diversas. Vendiam suas peças de coleção num valor muito superior ao da maioria dos artesãos que se dedicavam à comercialização de linhas decorativas ou utilitárias. Com relativa frequência, apareciam nos meios de comunicação, tais como, revistas, jornais e televisão.Viajavam a muitos estados da República Mexicana e internacionalmente (especialmente a Estados Unidos). Gostavam de arte e se consideravam artesãos que faziam arte, dado que exerciam um oficio que havia sido herdado de geração em geração.

Esta família não era um caso isolado no contexto artesanal tonalteca, onde pude observar que a figura do artesão-artista se gestava, quase que por regra, pela sua participação nos concursos de artesanato. Tais eventos possuem certas normas a seguir, entre as quais, é imperativo que o artesão apresente um trabalho novo, original e que vincule as técnicas tradicionais com uma visão "moderna" e distinta do oficio ${ }^{2}$. Ser um artesão de concurso gera distinção entre aqueles que nunca participaram ou que não receberam prêmio e reconhecimentos por tal atividade. Esta distinção tem seu lado positivo e negativo, porque ao mesmo tempo, enaltece

1 Zepeda, Carlos (2015) "Artesanos de Jalisco arrasan en premios de arte popular", en: El Milenio, disponible en:http://www.milenio.com/cultura/ Joveens_Arte_Popular-concurso_artesania-Instituto_Artesania_Jalisciense_0_567543317.html

2 Num dos mais recentes concursos de artesanato, intitulada como "Galardón Jalisco 2015", nas regras de participação, se solicitava que fossem apresentados trabalhos com as seguintes características: "elaboração de obras com técnicas, materiais e design tradicional, assim como, novas propostas de peças com inovação baseadas na tradição cultural". Fuente: página web del Instituto de la Artesanía Jalisciense, http://www.jalisco. gob.mx/es/gobierno/organismos/1801 
alguns e exclui a outros. No caso da família Jimón, que vem construindo uma sólida trajetória como participantes e premiados em concursos, há uma visão positiva dos mesmos, como podemos observar neste fragmento de entrevista:

(...) pois bem, penso que os concursos te motivam, motivam o artesão para que se esforce, e ainda mais quando te reconhecem e pois, ganhas um prêmio! Por esse lado, vejo como algo muito bom que realizem os concursos para os artesãos e não se acabe isto, para que a gente se esforce (Fernando Jimón Melchor, 2010, Tonalá, tradução livre da autora).

Como comentei anteriormente, criar uma peça de concurso costuma levar meses de trabalho. Os concursos se caracterizam então, por defender a conservação das tradições e saberes populares, e ao mesmo tempo, fomentam a criatividade e a competitividade entre os participantes, especialmente, a figura do artesão como autor individual do trabalho.

Mas nem sempre as diferenças e semelhanças entre "tradição" e "inovação" são complemente entendidas pelos artífices e muito menos, os critérios de julgamento e as preferências dos jurados por certas obras em virtude de outras: "sempre ganham os mesmos, e desse jeito, eu não tenho vontade de me esforçar para fazer algo melhor porque sabes que sempre vão ganhar os mesmos" (Artesão de Coroneo, 2014, tradução livre da autora).

Nas imagens a seguir, podemos observar o casal Fernando e María Elena ${ }^{3}$, artesãos-artistas que posam junto a seus reconhecimentos e prêmios artesanais. Cada um deles possui um estilo de trabalho e imprimem características próprias nas peças que realizam: Fernando trabalha peças maiores e mais complexas, como se fossem quebra-cabeças, enquanto que María Elena prefere trabalhar as miniaturas em barro. $\mathrm{Na}$ casa

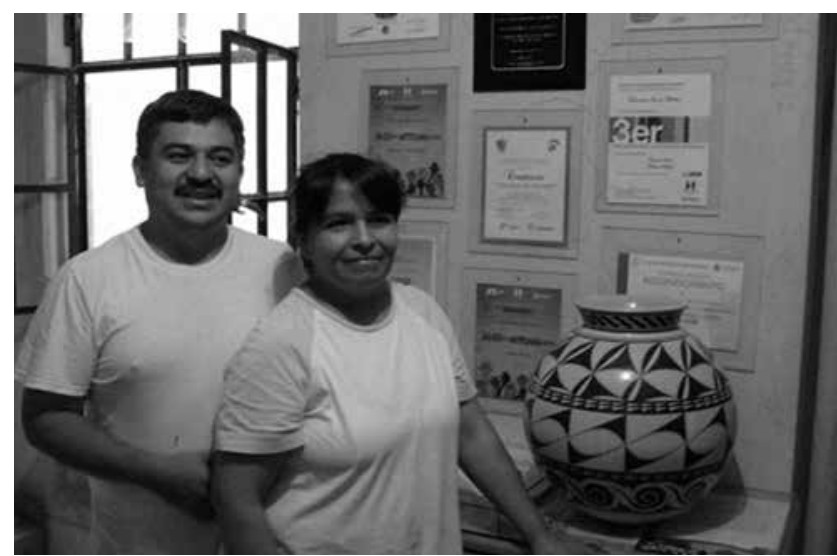

Figura 4 - Fernando Jimón Melchor e María Elena López, tonaltecas mostrando seus prêmios em concursos de artesanato. Fotografia: Vanessa Freitag, Tonalá, 2010. deles organizaram uma espécie de galeria particular a fim de expôr as melhores peças criadas pela família. Mas o interessante deste caso é que também colecionavam obras artesanais criadas por outros artesãos da localidade.

De acordo com estes artesãos, ao mesmo tempo em que aprenderam a valorizar os objetos que criavam também reconheceram a necessidade de pensar num espaço especialmente dedicado à exibição desses trabalhos. Esta iniciativa se deu depois de observarem o modo como eram expostas as peças artesanais nos concursos e nos museus. A iniciativa foi vista de maneira positiva pelos demais integrantes da família, como podemos observar no comentário que faz um familiar de Fernando Jimón Melchor:

(...) Gostaria que aquela parte da casa, que está aí na entrada, tê-la como uma peça para exibição. Deixá-la exclusivamente para pôr os trabalhos, para pôr umas bases e na parede, alguns pratos. Uma peça de exibição e que cheguem os clientes e as vejam, não é? Para mostrar os trabalhos que fazemos, ou seja, por quê não conservá-los? Por quê não guardá-los? Cuidá-los? Para quando cheguem os clientes, se possa explicar que estes trabalhos participaram nos concursos (Fernando Jimón Barba, 2010, Tonalá, tradução livre da autora).

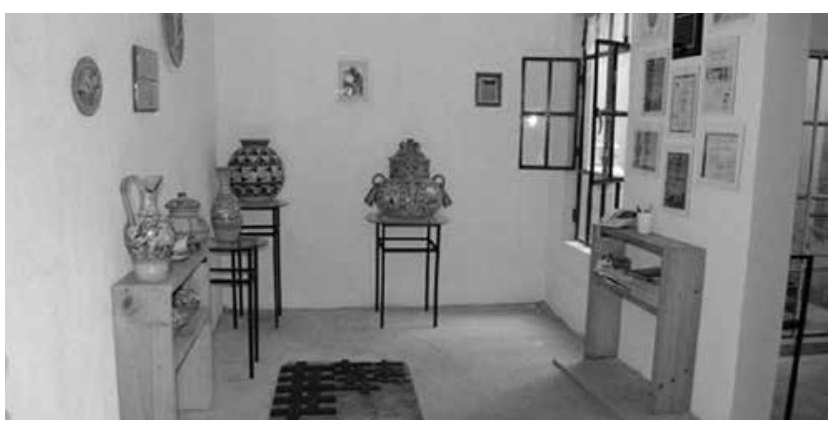

Figura 5. - Galeria particular de Maria Elena e Fernando. Fotografia. Vanessa Freitag, Tonalá, 2010.

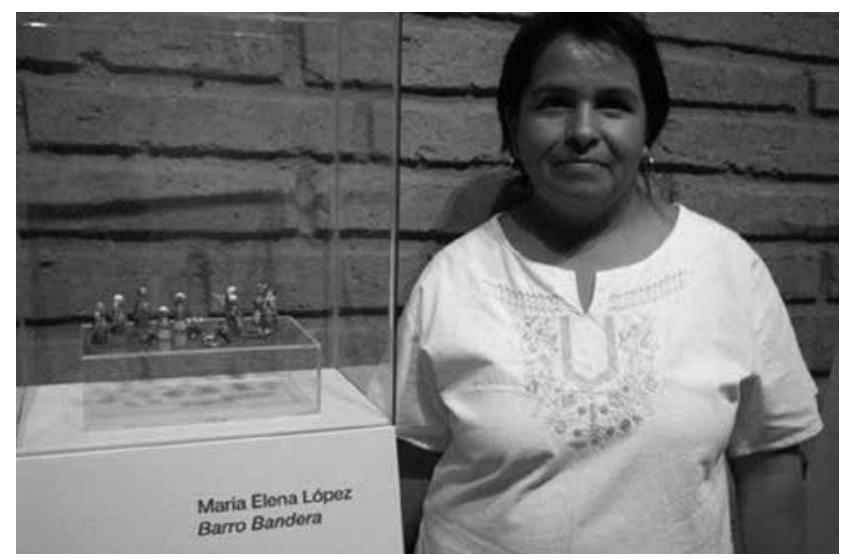

Figura 6 - Maria Elena López e suas miniaturas expostas num museu local.Fotografia: Vanessa Freitag, Tonalá, 2010.

3 Tanto a imagem dos artesãos e dos seus trabalhos usadas neste texto foram previamente autorizadas pelas famílias de artesãos por considerarem um modo de difundir o que faziam. 


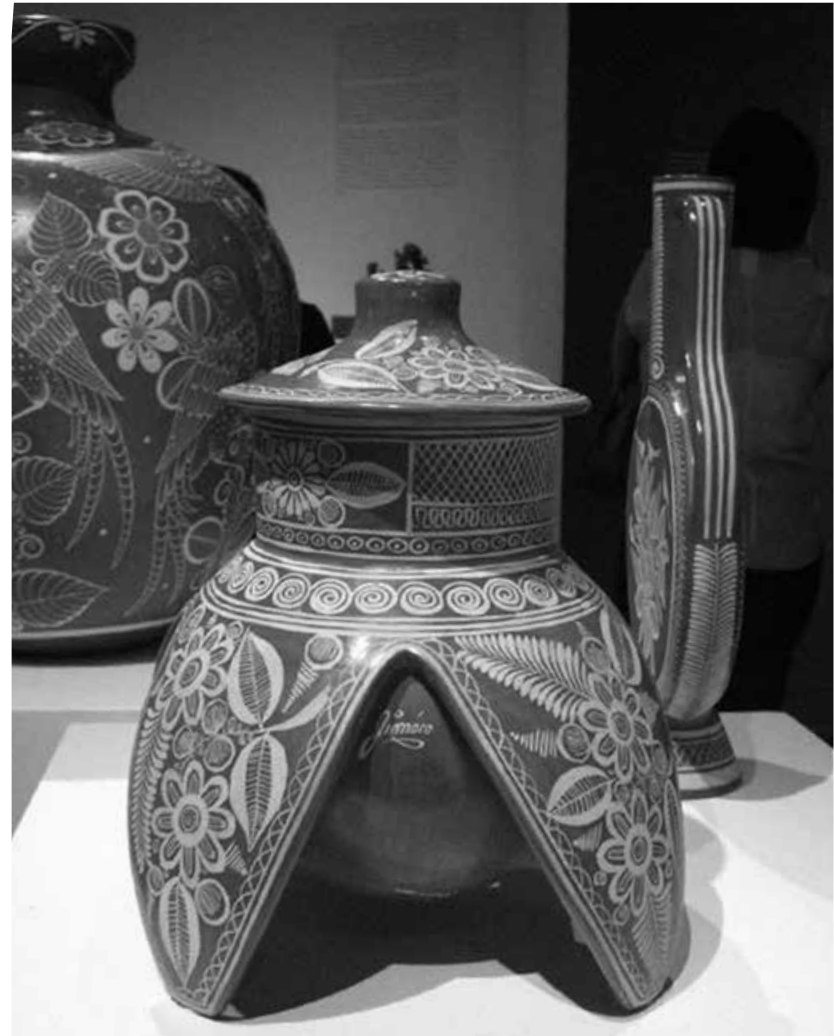

Figura 7 - Artesanato em barro bruñido da família Jimón e exposto em museu local. Fotografia: Fernando Jimón Melchor, Tonalá,2014.

De acordo com Bourdieu (2010), as necessidades culturais são produto da educação. Certas práticas culturais, tais como, freqüentar museus, exposições, concertos, o gosto pela leitura, entre outros, e a preferência por determinados artistas e escritores estão estreitamente relacionadas com o nível de instrução e a classe social dos sujeitos. De certa forma, frequentar museus "educou" o olhar desses artesãos-artistas sobre o tipo de trabalho que costumam criar, além de proporcionar-lhes uma visão otimista do oficio, como podemos observar no testemunho a seguir:

(...) Gosto deste oficio porque me deu muitas satisfações e porque tem muitíssimo futuro e podemos conseguir muitíssimas coisas boas. Talvez já não de forma comercial mas sim, de forma cultural. Adoro a ideia de me desafiar para criar uma peça diferente, nova (Fernando Jimón Melchor, 2010, Tonalá, tradução livre da autora).

Esta família é um exemplo que expressa as características do artesão-artista: num primeiro momento, desacomoda nosso sentido comum de que artesãos não sabem agenciar seus objetos, de que permanecem passivos esperando a chegada dos compradores. Como pudemos observar, alguns artesãos mexicanos se diversificam ao ponto de expor em museus e galerias; elaboram peças sofisticadas pensando num tipo específico de comprador: os colecionadores de arte ou o público interessado por um objeto artesanal exclusivo e único; e participam de concursos de artesanato. Em outras

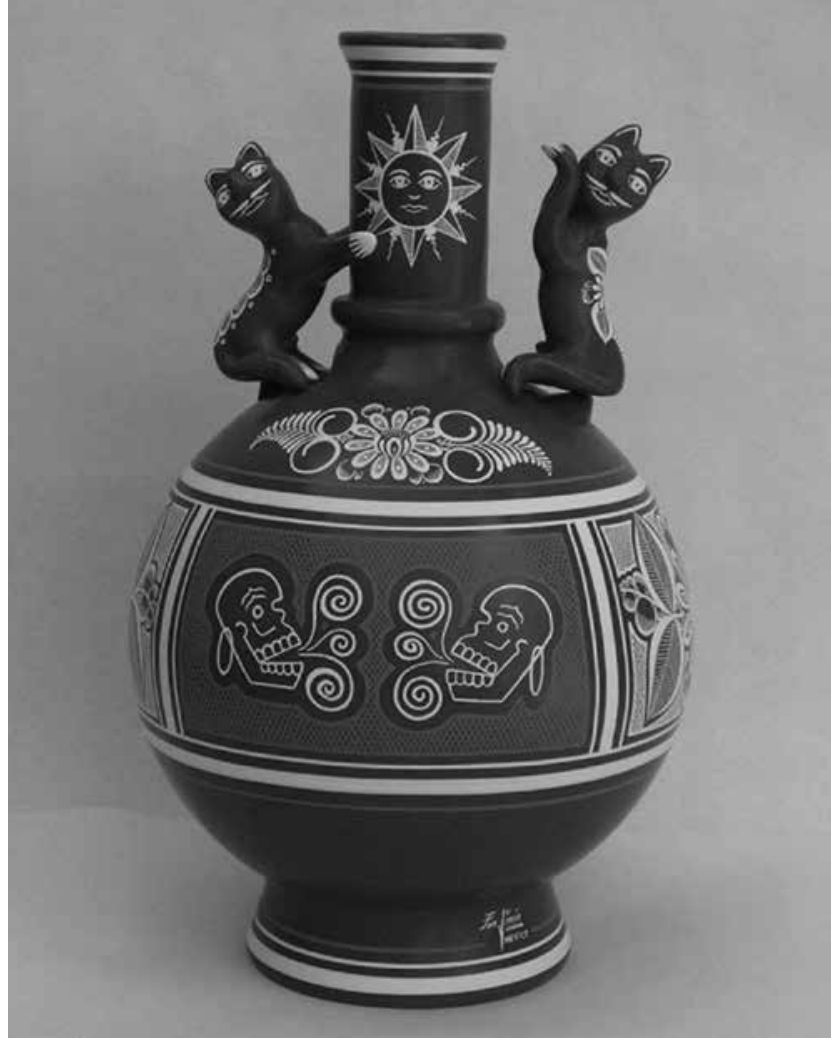

Figura 8. Artesanato em barro bandera da família Jimón e exposto em museu local.Fotografia: Fernando Jimón Melchor, Tonalá,2014.

palavras, esses artesãos nos ensinam a ressignificar a prática artesanal como uma prática artística.

\section{Algumas considerações finais}

O propósito desse texto foi repensar a prática artesanal do artesão visto como artista tomando como estudo de caso, a produção de artesãos mexicanos. A partir das discussões sobre o conceito de artesão-artista, se propôs desdobrar conceitualmente, as particularidades, semelhanças e diferenças entre o trabalho artístico e artesanal. Como bem pudemos observar, o conceito de arte sofreu um processo de diferenciação e legitimação ao longo da historia, respondendo às necessidades e interesses criados por uma elite.

Hoje em dia, ser artista significa "não ser artesão" e ainda ser capaz de elaborar obras com características estéticas e conceituais diferentes da artesanal. Por outro lado, a atividade artesanal se diferenciou ao longo do tempo, ao ponto de encontrarmos com trabalhos artesanais que são criados e expostos para ser vistos como "obras de arte".

Sendo assim, tanto o trabalho artesanal como o artesanato devem ser entendidos em toda a sua complexidade, levando em consideração aspectos de ordem social, cultural e econômico que implicam diretamente na produção, circulação e consequentemente, a definição desses objetos (como arte ou artesanato).

Possivelmente, o caso aqui exposto nos brinda algumas pistas para pensar, sob que circunstâncias, alguns 
tipos de artesanato se convertem em arte. Primeiramente, me parece crucial entender o artesanato se tornou cada vez mais especializado e a maioria das pessoas desconhecem todas as atividades e tipos de objetos que são produzidos, posto que se costuma ter uma ideia bastante generalizada desta prática, como se pode apreciar neste artigo. A propósito, Davy (2011) nos lembra que é cada vez mais comum a criação de artesanato cuja finalidade principal (ou única) é a sua comercialização, ao mesmo tempo em que se desvanecem outros possíveis usos e significados dos mesmos. Por último, poderia afirmar que quando um objeto artesanal se converte em arte, significa que foi "desviado" de seu propósito tradicional e adquire outras características ou funções: "os objetos produzidos por pequenas comunidades com fins estéticos, ceremoniais ou suntuários, são transformados cultural, econômica e socialmente pelos gostos, mercados e as ideologias de economias maiores" (Appadurai, 1994, p.44).

O conceito de desviação me parece útil para pensar a mudança nos propósitos que incialmente tiveram os objetos artesanais. Em outras palavras, poderíamos dizer que houve uma "desviação do olhar" tanto de quem criou o artesanato com a finalidade artística, quanto de quem aprecia, compra, coleciona ou consome estas obras. Esta desviação me parece importante para que desacomodemos nossos juízos, carregados de preconceitos e desconhecimento sobre aquilo que deve ou não ser considerado arte ou artesanato.

De modo pessoal, concluo dizendo que o trabalho do artesão é um trabalho artístico, mas nem tudo o que se faz sob o nome de "artesanato" realmente tem a intenção de ser arte. Estou consciente de que este texto talvez não resolva na íntegra a problemática proposta, mas contribui como ponto de partida para seguir pensando sobre um problema que continua muito presente na atualidade e que possui, diferentes pontos de vista.

\section{Referências}

ANDRADE, Mario “O artista e o artesão”. 1938. Disponível em: http://www.eba.ufmg.br/alunos/kurtnavigator/arteartesanato/filos-03-artesao.html

APPADURAI, Arjun. La vida social de las cosas: perspectiva cultural de las mercancías. México: Grijalbo, 1991.

BASTIDE, Roger Arte y Sociedad. Fondo de Cultura Económica: México. 2006.

BECKER, Howard Art Worlds. University California Press: Berkely. 1982.

BELTING, Hans Antropología de la imagen. Katz Editores: España. 2007

BOURDIEU, Pierre El sentido social del gusto. Elementos para una sociología de la cultura. Siglo Veintiuno Editores: Buenos Aires. 2010.

COLOMBRES, Adolfo Teoría transcultural del arte. Hacia un pensamento visual independiente. Conaculta: México. 2014. DAVY, Damien Comercialización de artesanía indígena y noción de tradición en Guayana Francesa: hacia una nueva terminología. Mundo Amazónico, 2. 2011. p.43-66.

FISCHER, Ernst $A$ necessidade da arte. Editora Cortez: São Paulo. 1983.

FLORES BALLESTEROS, Elsa Lo nacional, lo local, lo regional en el Arte latinoamericano: de la modernidad a la globalización y la antiglobalización. Huellas, 3.2003. p.31-44.

FROTA, Lélia Coelho “Arte do povo”. 1979. Disponível em: http://www.museucasadopontal.com.br/sites/default/files/ artigos/pdf/Artigo\%202\%20Lelia\%20Coelho\%20Frota.pdf GELL, Alfred Art and argency. An anthropological theory. Clarendon Press: Oxford. 1998.

GOLDSTEIN, Ilana Seltzer "Arte, artesanato e arte popular: fronteiras movediças”. Em: HIKIJI, Rose Satiko Gitirana; SILVA, Adriana de Oliveira. Bixiga em artes e ofícios, Edusp, São Paulo. 2014. pp.01-15.

GOMES LIMA, Ricardo Arte popular e artesanato. Falamos da mesma coisa?. Ciências Humanas e Sociais em Revista Seropédica, v.31, n.1, Janeiro/Junho.2009. p.95-109.

GOOD, Catherine "La antropología del arte en México", en: ARAIZA HERNÁNDEZ, Elizabeth (Ed.), Las artes del ritual. Nuevas propuestas para la antropología del arte desde el occidente de México. El Colegio de Michoacán: Zamora. 2010.

KELLER, Paulo O artesanato em debate: Paulo Keller entrevista a Ricardo Gomes Lima. Revista Pós Ciências Sociais, v.8, n.15. 2011.

MARTÍNEZ-PEÑALOZA, Porfirio Arte popular en México, Panorama Editorial: México. 1981.

MICHAUD,Yves El arte en estado gaseoso. Ensayo sobre el triunfo de la estética. Fondo de Cultura Económica: México. 2007. NOVELO,Victoria Ser indio, artista y artesano en México. Espiral, No. 25,Vol. 9, septiembre-diciembre,.2002. pp.165-178.

. Las artesanías mexicanas, en: Florescano, E. (Coord.), El patrimonio nacional de México, II. Fondo de Cultura Económica: México. 1997. pp.111-129.

PAZ, Octavio El uso y la contemplación. Revista Camacol, vol.11, n.1.1988. p.120-125.

PÉREZ MARTÍNEZ, Herón "El sentido de las artesanías en el concierto de la cultura”. Comunicación presentada en el XXXII Coloquio de antropología e Historia Regionales, Zamora: México. 2010.

ROTAY MONTER, José A. Fernández de Antropología del arte y arte antropológico. Anales de la Fundación Joaquín Costa, n.07. 1990. p.55-62.

SENNETT, Richard El artesano, Editorial Anagrama: Barcelona. 2009.

SHINER, Larry La invención del arte. Una historia cultural. Paidós: Barcelona-Buenos Aires-México. 2010.

TABOSA, Adriana A perda do conceito original de arte. Revista O Olho da História, ano 11, no 8.2005. pp.01-10. Disponível em: http://www.oolhodahistoria.ufba.br/revista8.php ZAPATA, E. y SUÁREZ, B. Las artesanas, sus quehaceres en la organización y en el trabajo. Ra Ximhai. Revista de Sociedad, Cultura y Desarrollo Sustentable, 3. p. 591-620. México. 2007. 


\title{
Being craftsman and artist: the values of craft creative process
}

\begin{abstract}
The present paper has as objective a reflection to think about the craftsmanship of Mexican artisans that fall within the artistic circuit (through artistic exhibitions and participation in craft competitions). At the same time, it aims at to rethink the concepts of art and craft were built ideologically over time. Although craftsmen are renowned because of the excel in presenting works of great aesthetic and conceptual wealth, their works continue to be seen as socially crafts and valued as such. It is necessary to question the ways of seeing the craft currently taking into consideration the different typologies that characterize offices that have history and tradition.
\end{abstract}

Key Words: art, crafts, handcraft aesthetics, creative process, Mexican artisans.

\section{Ser artesano y artista: apuntes sobre el proceso creativo artesanal}

\section{Resumen}

El presente texto busca reflexionar sobre el trabajo artesanal de artesanos mexicanos que se insertan en el circuito del arte (a través de exposiciones artísticas y la participación en los concursos artesanales). A la vez, pretende repensar cómo los conceptos de arte y artesanías han sido construidos ideológicamente a lo largo del tiempo. En este sentido, aunque los artesanos se destaquen por presentar trabajos con gran riqueza estética y conceptual, sus obras siguen siendo vistas y valoradas socialmente como artesanías. Es importante crear un espacio para cuestionar los modos de ver a las artesanías actualmente tomando en consideración las diferentes tipologías que caracterizan los oficios de antigua raigambre.

Palabras-clave: arte, artesanías, estética artesanal, proceso creativo, artesanos mexicanos.

Data de recebimento: 09-10-2014

Data de aprovação: 20-10-2015 